\title{
A New EOR Technology: Gas Alternating Gas Injection
}

\author{
Mohammed A. Samba ${ }^{1}$, Ibrahim Aldokali ${ }^{1}$, Mahmoud O. Elsharafi ${ }^{2}$. \\ ${ }^{1}$ Member of Petroleum Engineering Department, Sebha University, Libya \\ ${ }^{2}$ McCoy School of Engineering, Midwestern State University, Wichita Falls, TX 76308, USA
}

\begin{abstract}
A new method of enhanced oil recovery has been developed and applied to a simulation using data for the fifth SPE paper " template from CMG ". The simulator was used in this paper is GEM in the Computer Modelling Group (CMG) advanced equation-of-state (EOS) compositional simulator. The new method is called Gas alternating gas injection (GAG). The Gas Alternating Gas process is a cyclic method of injecting alternating cycles of gas followed by gas and repeating. Sensitivity analysis showed this method can give a much better recovery factor for GAG compared with single continues gas injection. GAG benefits that will give low water cut and high oil recovery due to gas segregation between two gases and that will prevent heavier gas to go the top layers. This work indicate that the GAG injection is an economical method compared with continues injection. Especially when we use GAG $\left(\mathrm{Air}+\mathrm{CO}_{2}\right)$.
\end{abstract}

Keywords: Compositional Model; GAG; $\mathrm{N}_{2}$, CMG.

Corresponding Author: moh.samba@sebhau.edu.ly

\section{INTRODUCTION}

Enhanced oil recovery (EOR) refers to any reservoir process used to change the existing rock/oil/brine interactions (fluid/fluid interaction; fluid/rock interaction) in the reservoir in order to increase the oil recovery, and this interaction might reduce the interfacial tension, oil swelling, reduce oil viscosity; also wettability modification (Green \& Willhite, 1998). The following flow sheet shows the types of various EOR methods that are currently employed in the oil industry.

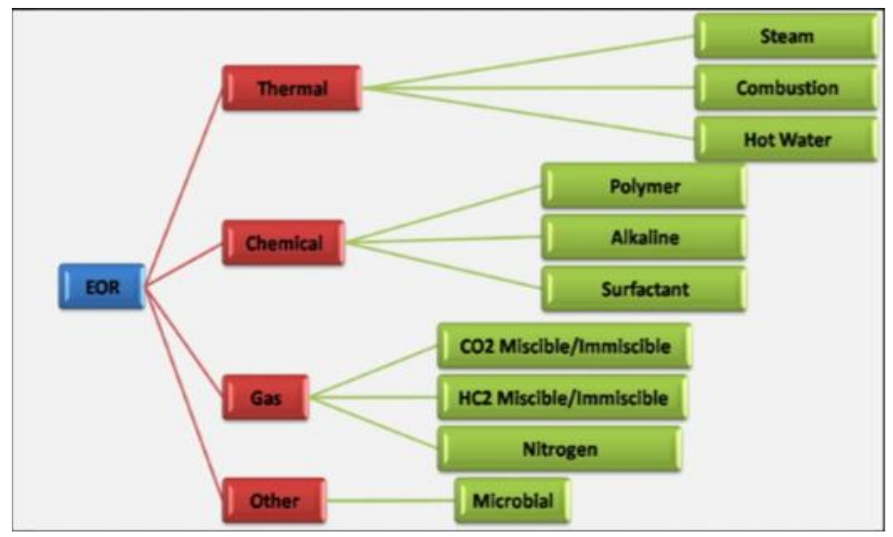

Fig. 1. Flow sheet for EOR methods (Samba, 2018)

Enhanced oil recovery (EOR) refers to any reservoir process used in order to increase the oil recovery. EOR has a lot of methods and every method has its own considerations to use it. One of those methods is the gas injection. The gas injection contains many types of gas injection such Hydrocarbon gas injection ( $\mathrm{HC})$, Carbon Dioxide $\left(\mathrm{CO}_{2}\right)$, Nitrogen $\left(\mathrm{N}_{2}\right)$ and Air injection.

The main purpose of the miscible gas slugs is to increase the microscopic sweep efficiency, but the most popular problem during the gas injection the gas will goes to the up layer (gravity override) if the suitable condition (high vertical permeability) has provided. And that will result high unswept area behind the injected fluid thus the macroscopic displacement efficiency will be low.

WAG injection has been introduced since 1958 (Caudle \& Dyes, 1958). The main purpose of WAG injection to increase the Macroscopic displacement efficiency, where the gas will tend to migrate to the top of the reservoir and the more dense water will tend to migrate to the bottom of the reservoir, hence 
attic oil in the upper parts of the reservoir may be contacted by the injected gas, at the same time the water flood will play as a piston to push forward the miscible slug and that is will increase the microscopic efficiency because the unswept reservoir area will be smaller.

WAG injection has proven a successful displacements application for various types of a reservoir with different types of rocks and location around all the world (Christensen, Stenby, \& Skauge, 1998). But one of the disadvantage of WAG injection is characterized by high water cut during the production life.

Early breakthrough is a common occurrence especially during the WAG injection. The mobility ratio plays an important factor to control the break through, an early breakthrough mostly occur when poor understanding of the reservoir heterogeneity happened. This problem is very critical to solve it. There are some fields reported that they closed their wells for a long time before the schedule due to the early breakthrough (Holloway \& Fitch, 1964).

Today we are going to add a new EOR technique to EOR world that will decrees the water cut during the production life, this method is called Gas Alternating Gas injection. The Gas Alternating Gas process is a cyclic method of injecting alternating cycles of gas followed by gas and repeating. The GAG injection mechanism is to inject to types of the gases (first slug and the second slug). Where the first slug of the gas should be lighter than the second slug of the gas injection. The basic theory for the first gas to be lighter due to the difference number of moles between two gases and that will lead the lighter gas will be in the upper layer and the heavier gas will be in the bottom layer due to the number of moles difference.

\section{A. Motivation to Apply GAG}

At the surface if the $\mathrm{CO}_{2}$ gas has been leaked, the $\mathrm{CO}_{2}$ gas will stay at the surface while the Air will rise up, the $\mathrm{CO}_{2}$ will stay at the bottom because it is heavier than the air.

\section{B. Simulation}

The simulator was used in this paper is GEM in the Computer Modelling Group (CMG) advanced equation-of-state (EOS) compositional simulator which includes a lot of options such as equation-ofstate, dual porosity, $\mathrm{CO}_{2}$, miscible gases, volatile oil, gas condensate, horizontal wells, well management, complex phase behaviour among others.

The data was used based on the Fifth Comparative Solution Project (fifth SPE paper): Evaluation of Miscible Flood Simulators. Where the template for miscible WAG has been provided from GEM-CMG (Computer Modeling Group) templates, the template has been modified based on the requirements for the of the inputs parameter for GAG flooding.

One injector and one producer were used to test GAG method to enhance the oil recovery. A 7 by 7 by 3 finite difference grids was used as shown in Fig.2.

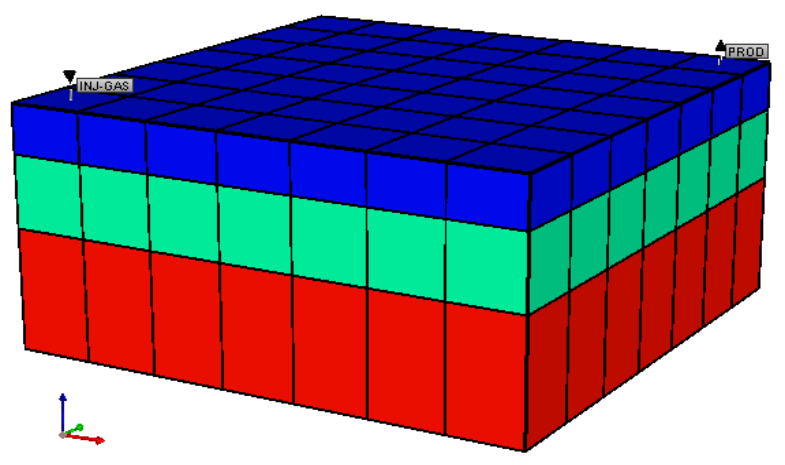

Fig. 2. Three-dimensional finite differences grid. 


\section{Simulation Period}

\section{Base Case}

The simulation time run for 18 years. The first two years was used for natural depletion, after the first two years the injection will start for all the scenarios. The GAG cycle was fixed for 8 years for the base case; this means the production constrains will be as the following:

0.0 To $<2$ Production.

2.0 to $<10$ Years first gas slug Plus Production.

10 to $<18$ Years first gas slug Plus Production.

Numerous simulations have been done to compare different EOR mechanisms; Air, $\mathrm{CO}_{2}, \mathrm{~N}_{2}, \mathrm{H}_{2} \mathrm{~S}, \mathrm{~N}_{2}$ also included GAG $\left(\mathrm{Air}+\mathrm{CO}_{2}\right), \mathrm{GAG}\left(\mathrm{N}_{2}+\mathrm{CO}_{2}\right)$ and $\mathrm{GAG}\left(\mathrm{H} 2 \mathrm{~s}+\mathrm{CO}_{2}\right)$.

\section{RESULTS}

\section{A. Sensitivity Analysis for Different Gas Type}

Fig. 3 shows the results for the continues gas injection Air, $\mathrm{CO}_{2}, \mathrm{H}_{2} \mathrm{~S}, \mathrm{~N}_{2}, \mathrm{GAG}$ (Air $+\mathrm{CO}_{2}$ ), GAG $\left(\mathrm{N}_{2}+\right.$ $\left.\mathrm{CO}_{2}\right)$ and $\mathrm{GAG}\left(\mathrm{H}_{2} \mathrm{~S}+\mathrm{CO}_{2}\right)$. Where $\mathrm{GAG}\left(\mathrm{H}_{2} \mathrm{~S}+\mathrm{CO}_{2}\right)$ has given higher oil recovery compared with other EOR methods. The recovery factor for GAG (Air $+\mathrm{CO} 2$ ) is $74 \%$. During the $\mathrm{H}_{2} \mathrm{~S}$ injection the recovery factor is lower but after the $\mathrm{CO}_{2}$ injection has been injected, strong increasing oil recovery has been noticed, the increasing of the oil recovery due to two reasons, the first reason is the miscible $\mathrm{H}_{2} \mathrm{~S}$ with oil create a suitable composition for $\mathrm{CO}_{2}$ injection to get miscible with oil and give the ability to enhance more oil. The second reason due to the gravity segregation between the $\mathrm{H}_{2} \mathrm{~S}$ and $\mathrm{CO}_{2}$ injection. Where the $\mathrm{CO}_{2}$ is heavier than the $\mathrm{H}_{2} \mathrm{~S}$ and that will improve the areal sweep efficiency, thus the recovery factor will increase.

The GAG (Air $+\mathrm{CO}_{2}$ ) gave the same recovery factor for the continues $\mathrm{CO}_{2}$ injection and that will give an advantage for GAG. As have known that the $\mathrm{CO}_{2}$ is more expensive than the Air, during the GAG the cumulative $\mathrm{CO}_{2}$ injection will be higher during the continues $\mathrm{CO}_{2}$ injection. Thus the GAG injection is more economy than the continues gas injection.

As shown in the Fig. 3 GAG has proven gave higher oil recovery compared with the WAG injection. Fig. 4 shown how GAG give low water cut compared with the WAG injection projects. Thus GAG can be applied for fields that have been reported shut in due to higher water cut.

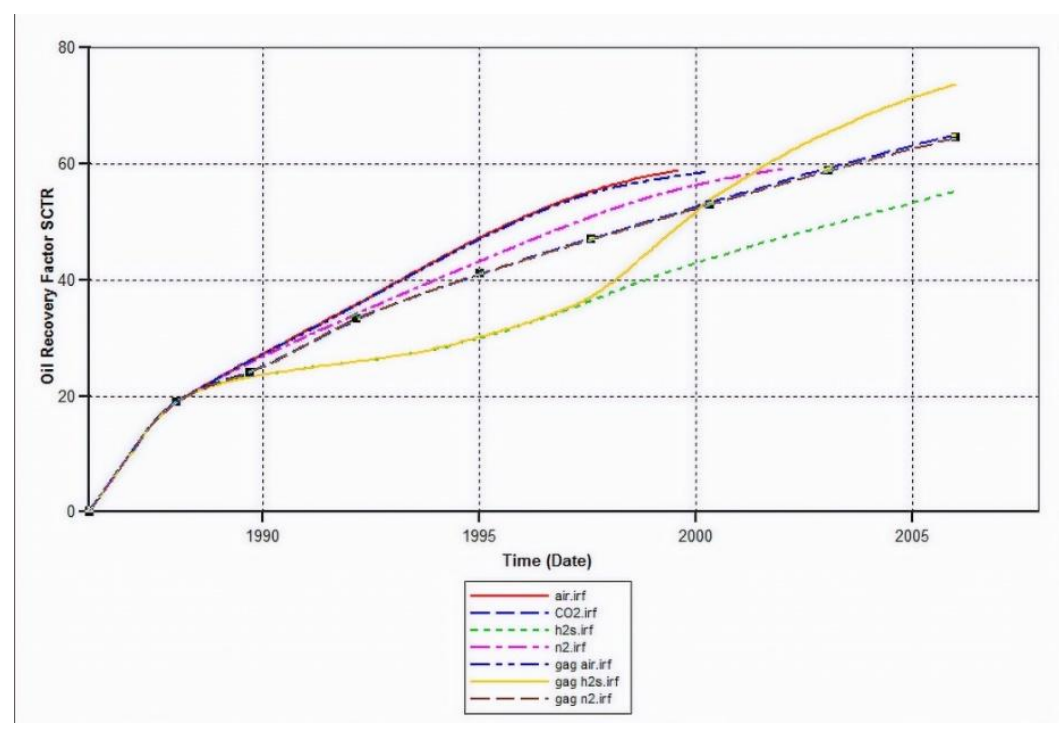

Fig. 3. Sensitivity analysis for different gas type (oil recovery). 


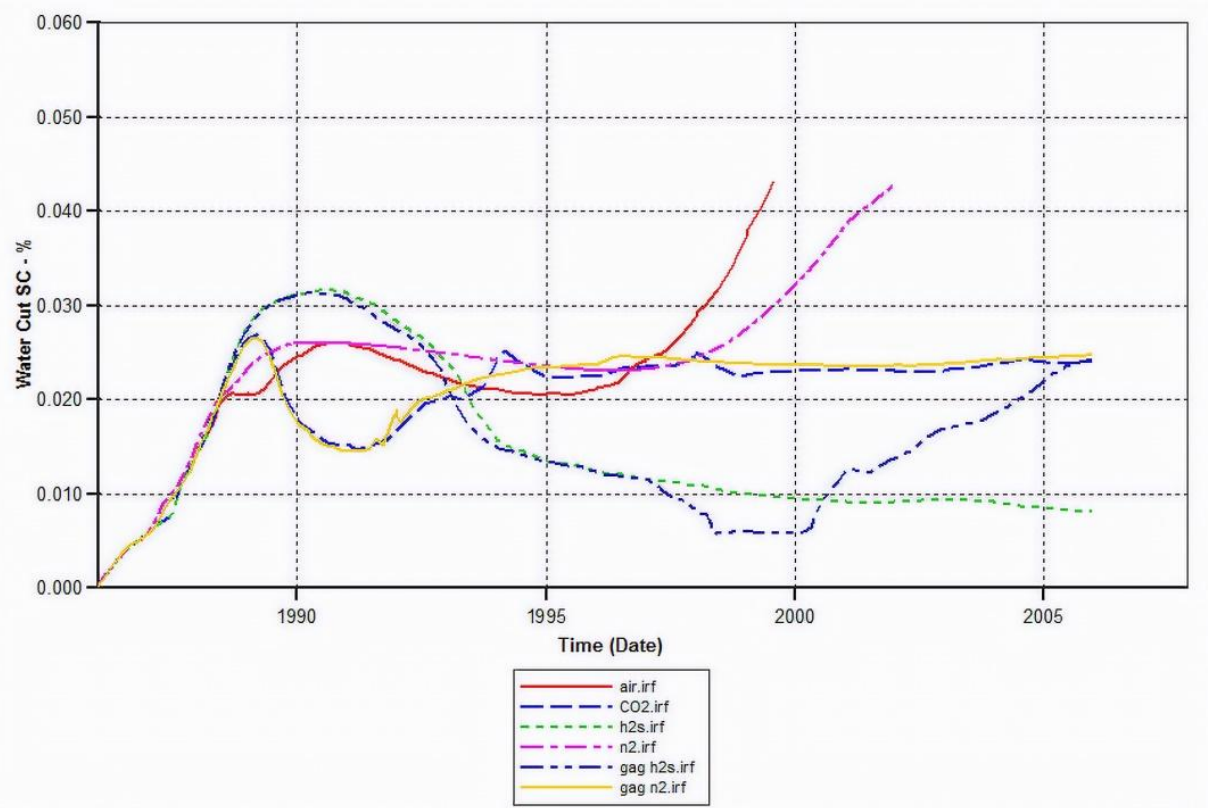

Fig. 4. Sensitivity analysis for different gas type (water cut)

\section{B. The Effect of the GAG Cycle on the Oil Recovery}

The GAG cycle is defined as the duration of alternating gas between each other. After the GAG $\left(\mathrm{H}_{2} \mathrm{~S}+\mathrm{CO}_{2}\right)$ injection gave a higher recovery factor we decided to run a cycle sensitivity analysis for the best case that has been obtained and obtain the effect of the GAG cycle on the oil recovery. The GAG cycle included 1 year, 2 years, 3 years and 4 years.

As shown in the Fig. 5, the GAG has no effect on the oil recovery if the same cumulative gas injection especially at the last date, For example, after 1995 days since started the injection, the cycle of 1 year has given lower recovery factor compared with other cycles, while at the end of of injection period has given the same recovery factor for all cycles. Thus, to choose the GAG cycle will be depends on the company decisions and politics based on it is contract ( type and finished date contract)for fields and other consideration will be included.

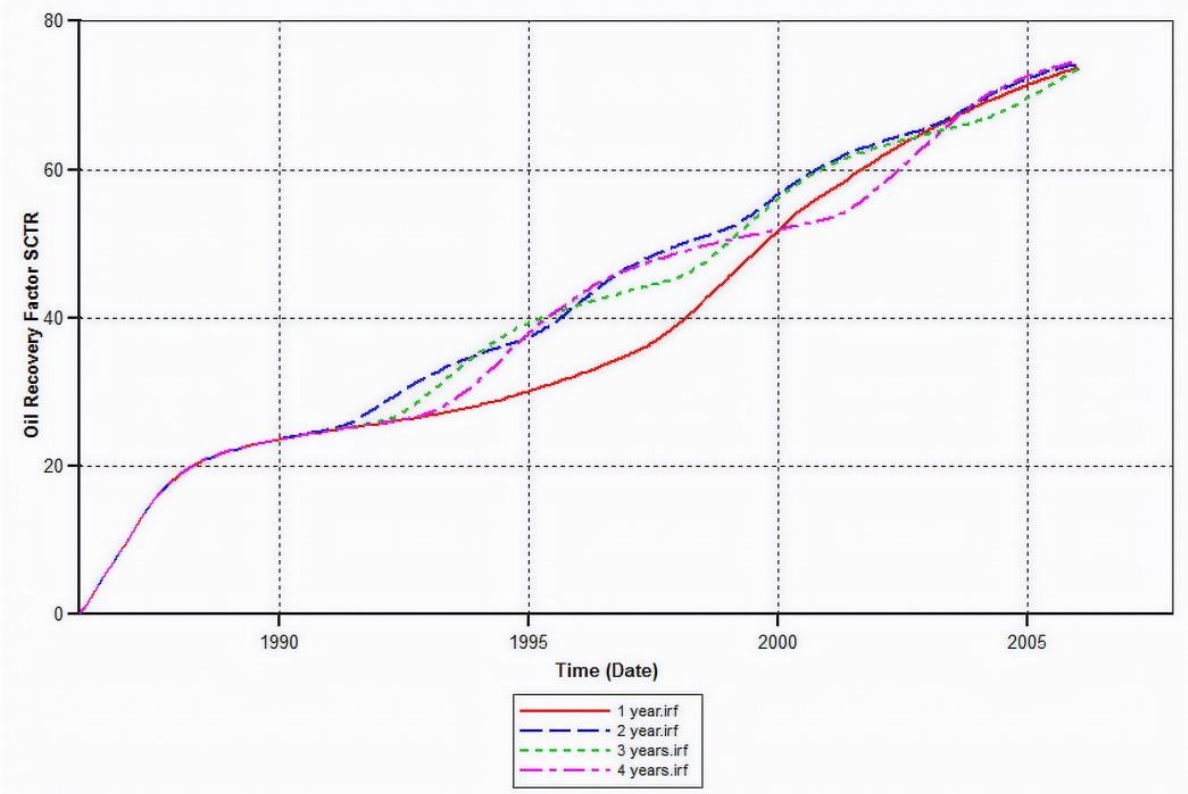

Fig. 5. Effect of the GAG cycle on the oil recovery.

\section{The Effect of the GAG Ratio on the Oil Recovery}


The ratio of the volume of first slug to the volume of a second slug injected it calls the GAG ratio. This factors play an important factor during GAG design especially to improve the economic side of projects especially when the one slug is cheap.

Fig. 6 shows the sensitivity analysis for GAG ratio, in this figure has shown the oil recovery does not depend on inject high quantity of the gas to recover more oil. GAG ratio 1:2 gave higher oil recovery compared with the other GAG ratios. Even at GAG ratio 1:3 gives less oil recovery than 1:2, while during the 1:3 the amount of the $\mathrm{H}_{2} \mathrm{~S}$ that has been injected is higher than when it compared with GAG ratio $1: 2$.

During the GAG ratio 1:1gave the same oil recovery with GAG ratio 1:3, this is one of advantage of sensitivity analysis of GAG ratio for any fields. The sensitivity analysis for the GAG ratio will give us economic prediction for the volume injection as shown table 1.

Table1 Sensitivity Analysis for GAG Ratio

\begin{tabular}{ccccc}
\hline Scenario & $\begin{array}{c}\text { GAG } \\
\text { Ratio }\end{array}$ & $\begin{array}{c}\text { Gas Rate } \mathbf{C O}_{2} \\
\left(\mathbf{f t}^{3} / \mathbf{D}\right)\end{array}$ & $\begin{array}{c}\text { Gas Rate } \mathbf{H}_{2} \mathbf{S} \\
\left(\mathbf{f t} \mathbf{f}^{3} / \mathbf{D}\right)\end{array}$ & $\begin{array}{c}\text { Gas Rate } \mathbf{C O}_{\mathbf{2}} \\
\left(\mathbf{f t}^{3} / \mathbf{D}\right)\end{array}$ \\
\hline 1 & $1: 1$ & $12,000,000$ & $12,000,000$ & 74 \\
\hline 2 & $1: 1.5$ & $12,000,000$ & $18,000,000$ & 80 \\
\hline 3 & $1: 2$ & $12,000,000$ & $24,000,000$ & 84.7 \\
\hline 4 & $1: 3$ & $12,000,000$ & $36,000,000$ & 74.4 \\
\hline 5 & $1.5: 1$ & $12,000,000$ & $8,000,000$ & 66 \\
\hline 6 & $2: 1$ & $12,000,000$ & $6,000,000$ & 61.4 \\
\hline
\end{tabular}

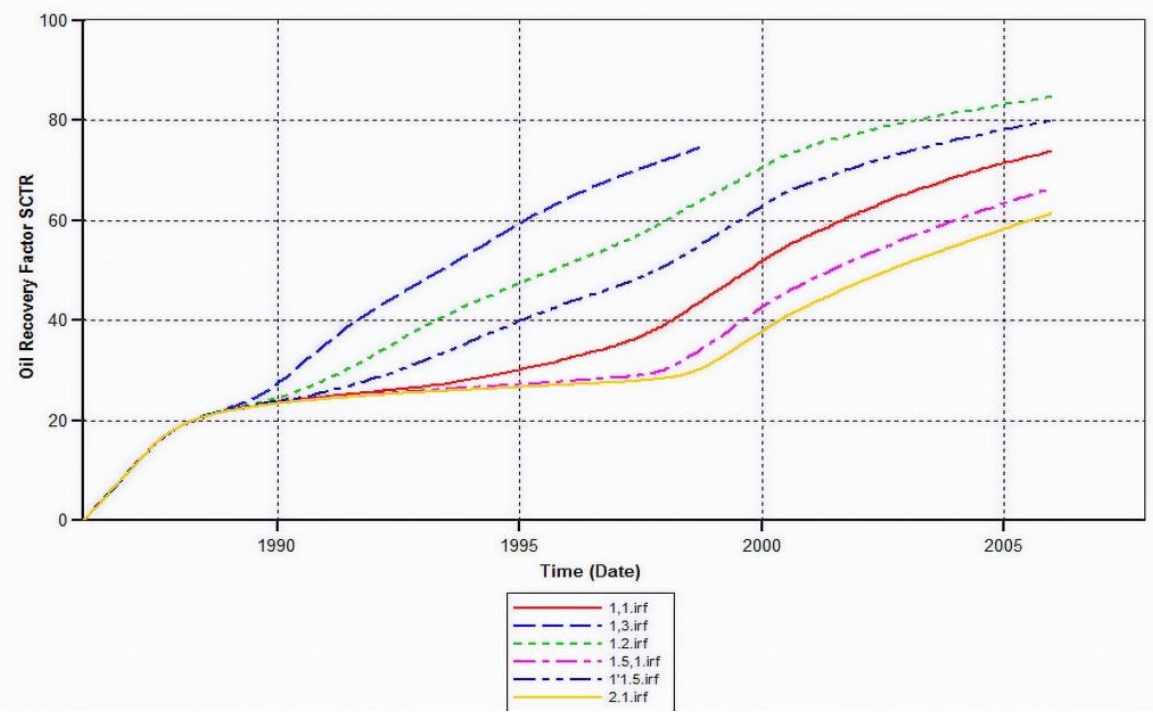

Fig. 1. Effect of the GAG ratio on the oil recovery.

\section{Reverseof Slug Volume}

This scenario included the best scenario for the GAG ratio sensitivity analysis. Fig. 7 shows the first slug in this scenario is $\mathrm{CO}_{2}$ while the $\mathrm{H}_{2} \mathrm{~S}$ slug has injected as the second slug. The reverse of the slug volume also play an important factor especially when the company decision are on the stake. When $\mathrm{H}_{2} \mathrm{~S}$ injected as the first slug has given higher oil recovery due to the gravity difference between the $\mathrm{H} 2 \mathrm{~S}$ and $\mathrm{CO}_{2}$. 


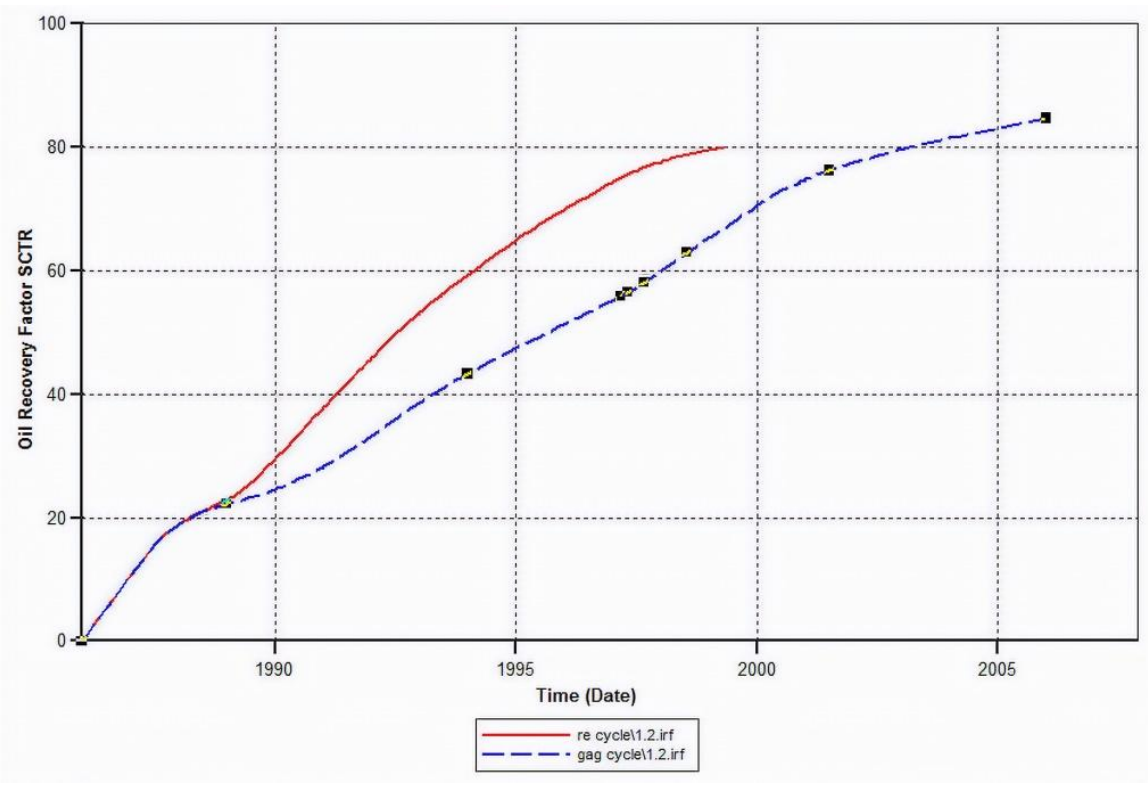

Fig. 7. Effect of the Reverse of Slug Volume.

\section{CONCLUSIONS}

1. In this study we introduced a new EOR scheme and it compared against some other EOR schemes. This EOR scheme which is a combination of the two favorable commercial schemes, continues gas injection Air, N2, $\mathrm{Co} 2, \mathrm{H} 2 \mathrm{~s}$, GAG $\left(\mathrm{Air}+\mathrm{CO}_{2}\right)$, GAG $\left(\mathrm{N}_{2}+\mathrm{CO}_{2}\right)$ and $\mathrm{GAG}\left(\mathrm{H} 2 \mathrm{~s}+\mathrm{CO}_{2}\right)$. Where GAG shows a significant improvement in incremental recovery. In addition it has less injectivity problem as the well has less water cut compared with WAG injection.

2. GAG has proven as an economical method compred with continues injection. Especially when we use GAG (Air $\left.+\mathrm{CO}_{2}\right)$ Air injection doesn't need a source near from the field.

3. GAG cycle has no effect on the oil recovery in this field if the same cumulative gas injection especially at the last date.

4. GAG ratio is a useful tool that give an economical prediction for the volume of gas injection.

\section{REFERENCES}

Caudle, B. H., \& Dyes, A. B. (1958). Improving Miscible Displacement by Gas-Water Injection. Society of Petroleum Engineers. Retrieved from https://doi.org/

Christensen, J. R., Stenby, E. H., \& Skauge, A. (1998). Review of WAG Field Experience. International Petroleum Conference and Exhibition of Mexico. Villahermosa, Mexico: Society of Petroleum Engineers. https://doi.org/10.2118/39883-MS

Green, D. W., \& Willhite, G. P. (1998). Enhanced Oil Recovery. Henry L. Doherty Memorial Fund of AIME, Society of Petroleum Engineers. Retrieved from https://books.google.co.id/books?id=0cUWAAAACAAJ

Holloway, H. D., \& Fitch, R. A. (1964). Performance of a miscible flood with alternate gas-water displacement. Journal of Petroleum Technology, 16(04), 372-376.

Samba, mohammed A. (2018). Literature Review of Water Alternation Gas Injection. Journal of Earth Energy Engineering; Vol 7 No 2 (2018): OCTOBERDO - 10.25299/Jeee.2018.Vol7(2).2117. Retrieved from http://journal.uir.ac.id/index.php/JEEE/article/view/2117 